\title{
INDICATORS FOR WOMEN'S HEALTH IN DEVELOPING COUNTRIES: WHAT THEY REVEAL AND CONCEAL ${ }^{1}$
}

\section{Jerker Edström}

\section{INTRODUCTION}

There are at least two fundamentally different ways of approaching the issue of women's health in development. One would focus on gender differentials in health, such as health status, health expenditures, nutrition and so on, whereas the other would start by focusing on areas of health care which are specific to women, and affect their lives more directly than those of men. This article starts with the latter type of approach, but hopes to draw on aspects of other gender differentials in health, where these are directly relevant to the discussion. It is worth pointing out that gender differentials in age specific mortality rates in developing countries are most pronounced in the reproductive age groups (as well as in early childhood), when women suffer excess mortality over men. Whilst almost half of all deaths of women in these age groups, in districts of rural India or Bangladesh are connected with pregnancy, in countries like Sweden or Canada this proportion is close to nil (WHO 1989a). Although restricted to a reproductive health framework, this article argues that inquiries into women's health generally should seek to go beyond this sphere. It also attempts to show that the reproductive health of women cannot, itself, be analysed satisfactorily without reference to the broader issues encountered in the field of gender and development.

However, if we want to speak meaningfully about women's health as something in its own right, we should ensure that we have some reasonably objective points of reference, or indicators, by which to proceed. Further, it is crucial that one is clear about what those indicators actually mean. This article will analyse some gender specific health indicators which are currently widely used (especially with reference to maternal health), what we know about some of these and some of their limitations. That is, what they reveal and what they conceal.

\section{THE EVOLUTION OF PREDOMINANT INDICATORS FOR WOMEN'S HEALTH}

The 1960s and 1970s formed a more or less continuous period of increasing recognition of the complexity and interrelatedness of developmental problems. In the health policy debate, this trend culiminated in the international declaration of Primary Health Care (PHC), at Alma-Ata, in 1978. However, the complexity and multisectorality inherent in the PHC approach was set on a collision course with the approaching economic world recession of the early 1980 s and the accompanying right wing winds, which opposed redistribution, equality or the liberation of women from sexual oppression.

In an attempt to salvage the spirit of PHC within the constraints of budget cuts in health and other social sectors, the WHO and UNICEF articulated a set of priority interventions in the field of Maternal and Child Health $(\mathrm{MCH})$, which came to be known under the collective acronym GOBI-FFF. UNICEF and others proceeded to adopt an increasingly selective approach to health policy in what was labelled the 'GOBI strategy' for a, so called, Child Survival and Development Revolution (UNICEF 1985), and which focused exclusively on a few low cost interventions aimed directly at infants. The word 'development' was almost redundant, however, as the emphasis was uniquely on survival; the three ' $F$ ' in the original formula - which stood for family planning, female education and food supplementation - were largely ignored, as is reflected in UNICEF's shortening of the formula. The infant mortality rate was singled out as the primary indicator in health, and other indicators, such as the total fertility rate were practically discarded.

Occasional voices of dissent were raised and it became increasingly obvious that sustainable reductions in mortality would require more than a few selective interventions. The experience of several countries shows that institutional development and broad multisectoral development strategies can bring long term improvements at what actually turns out to be relatively low cost (Halstead, Walsh et al. 1985). The recognition of this, together with an increasing reaffirmation of the central role played by women in development has made policy makers increasingly

\footnotetext{
This article draws partly on work which I carried one to assist Dr Fred T. Sai, President of the Board of Directors of the International Planned Parenthood Federation (IPPF), in preparation for the 1991 Conference of the International Association for Maternal and Neonatal Health (IAMANEH). It also draws on ideas and
}

discussions with Erica Royston and Barbara Kwast at the Division of Family Health of the WHO, in Geneva, as well as with Alagnah Raikes at IDS. I thank them all for their contributions, but implicate none. 
acknowledge the need to broaden their approach to health policy and look at maternal health as being linked to infant and child health and, thus, to the health of the population in general (WHO 1987). A major turning point towards a broadening of the focus in health policy was marked by the Safe Motherhood Conference and the International Conference on Better Health for Women and Children through Family Planning, both held in Nairobi, Kenya, in 1987. The last four years have seen a revival in the field of maternal health and the maternal mortality rate has become the predominant indicator for reporting on women's health in developing countries. So, what exactly can information on maternal mortality tell us?

\section{COMMON CAUSES OF MATERNAL DEATHS AND BROAD SOCIOECONOMIC INDICATORS ASSOCIATED WITH MATERNAL MORTALITY}

\subsection{Common causes of maternal deaths}

The definition of a maternal death is the death of a woman whilst pregnant or within 42 days of its termination, from any cause related to or aggravated by the pregnancy or its management but not from incidental or accidental causes (WHO 1979). These deaths can be grouped into a) direct causes, resulting from pregnancy and childbirth and b) indirect causes, which are aggravated by the pregnancy or childbirth, whereas incidental, or non-obstetric deaths do not come under maternal mortality at all. The great majority of direct obstetric deaths are caused by haemorrhage, infections, toxemia, obstructed labour or complications from spontaneous or induced abortion. These causes account for approximately three quarters of maternal deaths in the Third World (Kwast 1989) and if anaemia, which is an indirect cause, is included, the proportion rises to roughly 80 per cent (WHO 1989a).

It is difficult to get accurate data on a global level, but findings from 11 population based studies from developing countries (Colombia, Cuba, Jamaica, Egypt, Ethiopia, Bangladesh, Indonesia and Papua New Guinea) give us a rough profile of the relative importance of these different causes of maternal deaths (Maine et al. 1987). Haemorrhage accounted for most deaths at 27.8 per cent on average, which was followed by induced abortion at 18.6 per cent, hypertension (or toxemia) at 16.8 per cent, infection (or sepsis) and obstructed labour at 11.4 per cent each and ruptured uterus at 5.8 per cent. However, the relative ranking of these major direct causes varies significantly in individual countries, depending on the level of health service development, social and economic factors as well as cultural practices.
Mortality from all these causes can normally be prevented with good obstetrical interventions and emergency treatment, but much can also be prevented earlier in pregnancy. Antenatal care plays a crucial role in the prevention of deaths from haemorrhage, anaemia, toxemia, obstructed labour or ruptured uterus. The early detection of high-risk pregnancies allows for referral to hospital for safer delivery. This raises the issue of the quality of assistance during delivery. The most effective precaution to reduce maternal mortality from sepsis, for example, is clearly asepsis and cleanliness during labour. Training health workers and birth attendants in better delivery practices is of major importance and improvements in personal and environmental hygiene within hospitals (or other premises for delivery) are essential in controlling infection.

Prevention of mortality from causes related to nutrition and physical development, such as anaemia or obstructed labour, can be approached at several levels. Raising the minimum age at marriage and providing family planning services can reduce the incidence of high risk teenage pregnancies and improved nutrition for young girls would reduce the incidence of obstructed labour due to poor pelvis development.

The incidence of induced abortion (whether legal or illegal) can, in the long term, be reduced through reducing the incidence of unwanted pregnancies by making family planning services available to those who require them. On the other hand, in the short and medium term, the only realistic way to reduce maternal deaths from abortions is by making sure that those abortions which are performed are done so legally and safely. There is no convincing evidence that illegal status of abortions actually result in fewer abortions being performed. On the contrary, evidence from several countries shows that the legalisation of abortion, and bringing it under the responsibility of official health services, reduces the incidence of maternal mortality related to abortion, (Liskin 1989; Potts et al. 1977).

\subsection{Socioeconomic factors associated with maternal mortality}

The full importance of various indirect causes of death, such as anaemia (resulting from under-nutrition and 'under-age'), may easily be overlooked by focusing uniquely on specific single causes of death, or by posing the question in a way which implies that each death is the result of one unique cause. In order to put the discussion in a broader framework, it is useful to consider broad socioeconomic indicators associated with maternal mortality. Data was collected from 26 different countries and a series of regression analyses 
Table 1: Results of simple and multiple regression of variables associated with maternal mortality and stepwise deletion of explanatory variables

Simple regressions

(I)
Multiple regression equations

(2) (3)

\section{Independent variable}

Log of GNP per capita

Proportions of births attended

by trained health staff

Proportion of total population

living in urban areas

Total fertility rate

Proportion of women in

childbearing age groups using

contraception

Proportion of girls in relevant age groups enrolled in secondary education

\section{R squared}

\section{Sample size}

$\begin{array}{cc}-1.154 & -0.859 \\ (-10.27)^{\star \star \star} & (-3.63)^{\star \star} \\ -0.018 & -0.010 \\ (-7.79)^{\star \star \star} & (-2.92)^{\star \star} \\ -0.025 & 0.000 \\ (-6.48)^{\star \star \star} & (0.06) \\ 0.364 & 0.026 \\ (6.91)^{\star \star \star} & (0.28) \\ -0.023 & 0.002 \\ (-5.72)^{\star \star \star} & (0.36) \\ & \\ -0.021 & 0.004 \\ (-5.49)^{\star \star \star} & (0.95) \\ & \\ 0.557-0.815 & 0.892 \\ 26 & 26\end{array}$

$-0.014$

$(-2.64)^{\star}$

0.240

$(2.09)^{\star}$

0.002

$(0.31)$

$-0.014$

$(-2.08)^{\star}$

$-0.001$

$(-0.21)$

$-0.011$

0.763

0.627

26

\section{Equations:}

(1) $\log M M R=a+b \star($ independent variable $)+c$

(2) $\log M M R=a+b^{\star}(\operatorname{LogGNP} /$ capita $)+c^{\star}(\%$ BA $)+d^{\star}(\%$ URBAN $)+e^{\star T F R}+f^{\star} C P+g \star(\%$ Female2ndEd $)+h$

(3) $\log M M R=a+b^{\star}(\%$ URBAN $)+c^{\star} T F R+d^{\star} C P+e^{\star}(\%$ Female2ndEd $)+f$

(4) $\log M M R=a+b^{\star} C P+c^{\star}(\%$ Female2ndEd $)+d$

Note:

$t$-values are given in parentheses under the coefficients for the independent variable. ${ }^{\star}=$ significant at the $95 \%$ confidence limit, $\star \star=$ significant at the $99 \%$ confidence limit, and $\star \star \star=$ significant at the $99.9 \%$ confidence limit. The coefficients are somewhat low for most variables, due to using a log-transformed scale for the maternal mortality rate, which will flatten the slope as high values are deemphasised.

Notation: $\log M M R=$ the logarithm of the maternal mortality rate (no. of maternal deaths $/ 100,000$ live births). $\% B A=$ Per cent of births attended by trained health staff, \%URBAN = Per cent of total population living in urban areas, TFR = the total fertility rate (average no. of live births per woman aged $15-45$, in her lifetime, assuming constant age-specific fertility rates to prevail), $\mathrm{CP}=$ contraceptive prevalence (per cent of women aged $15-45$, who are currently using some modern form of contraception), \%Female2ndEd = per cent of secondary school-aged girls enrolled in secondary education.

were performed. ${ }^{2}$ Countries were selected on the basis that data was available for all indicators thought to be relevant, in order to allow for comparability between the influences of different factors.

The full equations with coefficient values and statistical significance is given in Table 1 . Column 1 lists the results of regressing single variables with maternal mortality (on a log scale). Column 2 gives the results when controlling for all variables and Columns 3 and 4 show the effect of progressively deleting significant explanatory variables, to highlight intermediate variables.

maternal mortality in the World Bank Report referred to 1980 , national estimates were updated with more recent estimates from WHO, published in UNICEF's The Siate of the World's Children, 1991.
2 Countries were originally selected from the World Bank's World Development Report 1988 , on the basis that data was available for all indicators selected, for all countries. Countries for which maternal mortality estimates referred to hospital data, or specific rural locations, were deleted because of non-comparability. As data on 
The different indicators, which were all found to be correlated with maternal mortality when taken in isolation, were: 1) Poverty measured by the log of GNP per capita, 2) proportion of childbirths attended by trained health staff, 3) proportion of total population living in urban areas, 4) the total fertility rate, 5) contraceptive prevalence, and 6) proportion of relevant age group of girls enrolled in secondary education, in that order. However, when controlled for autocorrelation with each other, only the indicators for poverty and access to obstetric services retained independent statistical significance at a fundamental level.

\section{Poverty}

The level of GNP per capita was the indicator found to be most closely associated with maternal mortality and the relationship is a negative exponential one. As can be seen in Figure 1, maternal mortality rates fall substantially with even small increases in per capita GNP, whereas changes in already high per capita

Figure 1: The negative exponential relationship between maternal mortality and wealth, measured by GNP per capita

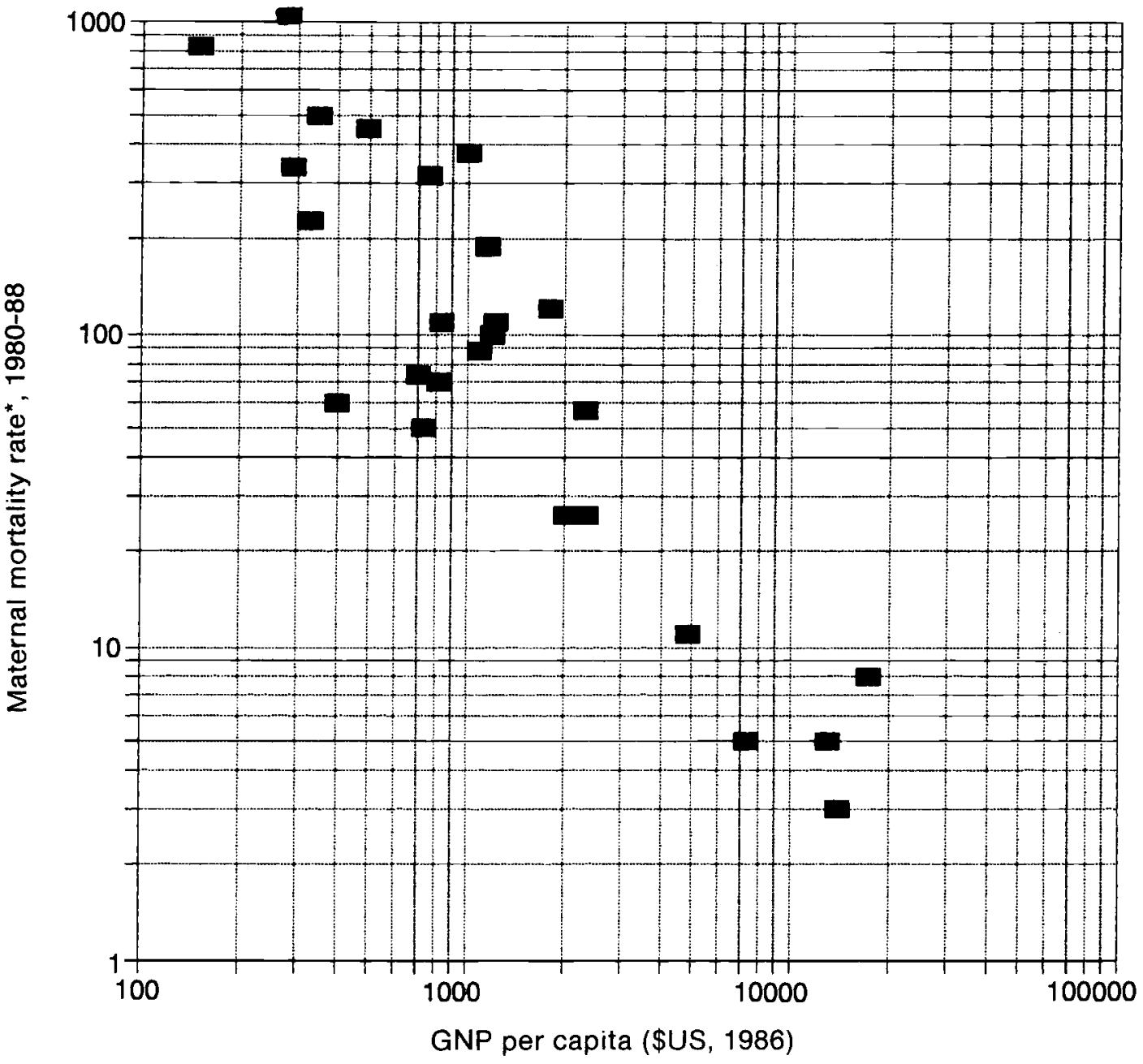

Note: ${ }^{\star}=$ maternal deaths per 100,000 live births on average, per year.

Source: Data are derived from the World Bank's World Development Report 1988 (for GNP per capita), and UNICEF's The State of the World's Children 1991 (for maternal mortality data - originally from the WHO). 
incomes are likely to be associated with relatively smaller variations in maternal mortality. As a rough guide, if one country, $A$, has a GNP per capita ten times larger than another country, $B$, then country $A$ is likely to have a maternal mortality rate ten times lower than country $\mathrm{B}$, and vice versa.

Poverty has an adverse impact on maternal health in several different ways. Some of these include reduced access to maternal obstetric health services, education and family planning services plus the fact that a great proportion of poor people tend to live in rural areas and have larger families. This is illustrated by the fact that, whilst all these other factors showed significant statistical associations with maternal mortality rates in isolation, their significance was greatly reduced in multiple regression.

Another important mechanism is likely to be via malnutrition. This interpretation appears particularly appropriate when one considers that we have no other indicator which would reflect this factor better in the equation. Hence, much of the independent significance of per capita incomes (on a log scale) is likely to be due to the 'confidence' of malnutrition and poverty.

Undernutrition during and prior to pregnancy can be highly dangerous, since pregnancy raises the nutritional requirements of the body. Deficiencies of iron, folic acid and other vitamins reduce the level of haemoglobin in the blood, which increases the mother's risk of anaemia (by reducing the capacity of the blood to carry oxygen). Calcium and vitamin $\mathrm{D}$ and other nutrients, are required for the normal development of the pelvic bone and they are particularly important for young women, who have not developed fully (the pelvis is often still growing at the age of 20). Malnutrition and undernutrition also increase a person's susceptibility to infections. Pelvic, genital and other infections may result in spontaneous abortion, ectopic pregnancy (and ruptured uterus), low birth weight babies and various congenital diseases of newborns (Winikoff 1988).

The relevance of classical nutrition supplementation programmes for pregnant women have frequently been questioned. To the extent that they could play a role, it may be that restricting their focus to the period of pregnancy is not the most effective approach (Winikoff health better may require an analysis of female nutrition throughout the reproductive life cycle; from 1988). Understanding nutritional status in maternal

birth and infancy throughout childhood, adolescence and pregnancy itself. In general however, the problem of malnutrition is so closely connected with that of poverty, that there is very little that can be done with respect to nutrition, in a sustainable manner, without enlisting the support of a general broad-based development strategy aimed at poverty reduction, with particular emphasis on food entitlements for women and young girls. Food insecurity and the related nutritional health risks to women are not only aggravated by poverty, but also by pervasive sex discrimination; and particularly by the combination of the two! ${ }^{3}$

\section{Lack of access to obstetric and maternal health services}

The only other major independently significant factor in determining maternal mortality (identified here) is 'access to maternal health and obstetric services', measured by the percentage of childbirths attended by trained health staff. This factor was associated with maternal mortality in a negative and highly significant relationship. Furthermore, it remained independently, and highly, significant when controlled for all other factors. This is not surprising, considering that a great majority of maternal deaths are preventable by good obstetric interventions, and it is reinforced by (and reinforces) evidence from country level studies, which suggests that access to adequate health services is a central determinant of the level of maternal mortality (Berardi, Richard et al. 1989). Clearly, a broad-based and aggressive anti-poverty development strategy is needed for sustainable improvements in maternal health, but it can not be a substitute for providing good obstetric and maternal health services. Rather, the two are complementary and the more detailed interrelationships need to be analysed further in order to design and implement realistic strategies for prevention.

\section{The status of women}

The status of women is often quoted as a root cause of maternal deaths. However, there is no one easily indentifiable indicator of this variable, since discrimination affects women's health in a range of different ways. Women's status in society is both strongly shaped by, and reflected in, various factors such as their fertility rate and their education. For want of a more global indicator, let us use the indicators of female secondary education, the total fertility rate and contraceptive prevalence as proxies of the status of women. ${ }^{4}$ These variables influence maternal health in different ways.

expect high abortion and still birth rates, and the inclusion of these in the denominator, would reduce the rate overall. relationship between various factors and maternal mortality emerges stronger on a $\log$ model of maternal mortality rate than a normal lincar model. Part of this explanation, however, may lie in the fact that inaternal mortality rates are likely to exaggerate the risks associated with pregnancy, since it excludes still births and abortions from the denominator; where maternal mortality is high one would
4 On reflection, it is not obvious that a global indicator would be particularly appropriate for informing policy and strategies for intervening to prevent maternal deaths. 


\section{Secondary education of girls}

The enrolment rate for girls, in secondary education, is negatively associated with the maternal mortality rate, if less strongly so than was the level of GNP per capita and the proportion of childbirths attended by health staff. Education gives young women better access to profitable employment and a wider range of career alternatives. It also reduces the incidence of high risk pregnancies, unwanted pregnancies and abortions, by increasing contraceptive use and reducing fertility. As girls stay in education for longer, the average age at marriage tends to rise as does the average age at first birth, providing family planning services are promoted and readily available. However, when these factors are controlled for the remainder of the effect of female secondary education on maternal mortality does not appear significant (see Column 2, in Table 1).

On the whole, however, education apparently reduces maternal mortality through its effect on, for example, contraceptive use and fertility.

\section{Fertility and contraceptive prevalence}

The total fertility rate and contraceptive prevalence are both significantly associated with maternal mortality rates, when taken in isolation. Controlling for the other variables takes away their independent significance, since they are strongly associated with secondary education of girls as well as by other factors, such as the degree of urbanization and per capita GNP. This supports the view that part of the influence of per capita incomes and female secondary education works through fertility, via contraceptive use (Mauldin and Segal 1988).

Where total fertility rates are high, women tend to experience their first pregnancy early in life, which increases the risks associated with first births. High total fertility rates also often coincide with continued childbearing into older ages as well as the fact that larger total numbers of births per woman mean shorter intervals between pregnancies. Each of these aspects imply increased risks to maternal health (Acsadi and Johnson-Acsadi 1986; Chen et al. 1974; Hobcraft 1987).

\section{Location of residence}

On the whole, women living in rural areas tend to suffer higher maternal mortality rates than do their urban counterparts. The degree of urbanization of countries' populations is negatively associated with their maternal mortality rates, when taken in isolation. On the whole, rural folk tend to be poorer, less educated and have higher fertility rates than do city dwellers, in developing countries. Illiteracy and large family size reinforces their poverty, which all compromises their access to services like education, health and family planning. Thus, when all these factors are controlled for, the independent significance of location of residence fades away.

The isolation, and lack of political representation, of rural dwellers make central governments reluctant to provide adequate medical services in sparsely populated regions. This is a highly critical problem in terms of maternal health, since rural women are more likely than most to be at high risk of developing complications in pregnancy and childbirth (Berardi, Richard et al. 1989). Hence, even though many contributing factors are encountered along the road to a maternal death, at the final stretch of the journey it is of ten the mere distance to adequate health services itself, which is responsible for the woman not receiving the medical attention she requires to save her life.

\subsection{Implications for selecting interventions}

Although analysing specific direct causes of death is not sufficient to appreciate the broader factors influencing maternal mortality levels, it is nevertheless needed to identify what can be done about the types of deaths which actually occur. Tackling a question from only one angle is not usually the most practical way of solving it.

Strategic alternatives for preventing maternal deaths range from surgical interventions and specialised obstetric emergency procedures, at one end of the spectrum, to broad community-based actions and nationwide reforms, at the other. A first step in laying out strategies for improving maternal health would be to systematically map out what needs to be done with respect to each major cause of death at different levels of intervention. This is not likely to produce a globally applicable 'prescription', but would have to be carried out separately for specific countries depending on the profiles of prevailing causes of death.

All major causes of maternal death can be attacked at the levels of i) nationwide policies and reforms, ii) community-based responses, iii) specific prevention programmes, iv) obstetric services and referral and, finally, v) follow-up (including preventive programmes such as family planning).

Table 2 shows how these strategies could be laid out and cross checked. Whereas some interventions, such as immunization against tetanus or the training of traditional birth attendants, would only impact on a small proportion of causes of death, other actions may have a broader reach. However, even though selective choices often have to be made to economise on resources, it is important that a good balance between different levels of interventions is achieved and maintained. 
Table 2: Framework for elaborating strategies for prevention of maternal deaths, by specific causes at various levels of intervention

\section{LEVEL OF INTERVENTION}

\begin{tabular}{|c|c|c|c|c|c|c|c|}
\hline CAUSE & $\begin{array}{l}\text { National } \\
\text { policies/ } \\
\text { reforms }\end{array}$ & $\begin{array}{l}\text { Local } \\
\text { action }\end{array}$ & $\begin{array}{l}\text { Specific } \\
\text { prevention } \\
\text { programmes }\end{array}$ & \multicolumn{2}{|c|}{$\begin{array}{l}\text { Treatment } \\
\text { and referral }\end{array}$} & \multicolumn{2}{|c|}{$\begin{array}{l}\text { Follow-up } \\
\text { programmes }\end{array}$} \\
\hline $\begin{array}{l}\text { Haemorrhage } \\
\text { (Blood loss) }\end{array}$ & HSR & AT & ANC & $\mathrm{OB}$ & BT & PNC & FP \\
\hline Abortion & $\begin{array}{l}\text { Laws } \\
\text { GSDS }\end{array}$ & & FP & $\begin{array}{l}\text { OB } \\
\text { Ref. }\end{array}$ & BT & Cou. & $\mathrm{FP}$ \\
\hline $\begin{array}{l}\text { Toxemia } \\
\text { (Hypertension) }\end{array}$ & HSR & $\mathrm{AT}$ & ANC NS & $\begin{array}{l}\text { OB } \\
\text { Ref. }\end{array}$ & BT & PNC & FP \\
\hline $\begin{array}{l}\text { Sepsis } \\
\text { (Infection) }\end{array}$ & HSR & AT & $\begin{array}{l}\text { ANC } \\
\text { TI }\end{array}$ & $\begin{array}{l}\text { OB } \\
\text { Ref. }\end{array}$ & BT & PNC & FP \\
\hline $\begin{array}{l}\text { Obstructed } \\
\text { labour and } \\
\text { rupture }\end{array}$ & $\begin{array}{l}\text { APD } \\
\text { HSR } \\
\text { GSDS }\end{array}$ & $\begin{array}{l}\text { AT } \\
\text { ICP }\end{array}$ & $\begin{array}{l}\text { FP } \\
\text { ANC NS }\end{array}$ & $\begin{array}{l}\text { OB } \\
\text { Ref. }\end{array}$ & BT & PNC & FP \\
\hline Anaemia & $\begin{array}{l}\text { APD } \\
\text { GSDS }\end{array}$ & $\begin{array}{l}\text { ICP } \\
\text { WIP }\end{array}$ & $\begin{array}{l}\text { ANC NS } \\
\text { FP }\end{array}$ & $\begin{array}{l}\text { OB } \\
\text { Ref. }\end{array}$ & BT & PNC & FP \\
\hline
\end{tabular}

Abbreviations: $\mathrm{HSR}=$ Health Sector Reform, APD $=$ Anti-Poverty Development, $\mathrm{GSDS}=$ Gender sensitive development strategies, ICP = Intersectoral Community-based Programmes, WIP = Women's Income generating Programmes, AT $=$ Alarm and Transport arrangements organised in the community, $\mathrm{TI}=$ Tetanus immunization, $\mathrm{TBA}=$ Training of birth attendants, ANC = Antenatal care, NS = Nutritional supplementation, FP = Family Planning, Cou $=$ Counselling, OB = Obstetric services, $\mathrm{BT}=$ Blood transfusion facilities, Ref. $=$ Referral, $\mathrm{PNC}=$ Postnatal care .

Note: This table is based on part of a similar table, I have drawn up in drafting a paper with Dr Fred Sai, which may be published. Whilst some of the abbreviations, titles and the range of causes are different, the same fundamental framework is applied.

\section{THE TOTAL FERTILITY RATE AND LIFETIME RISK OF MATERNAL DEATH AS ALTERNATIVE AND COMPLEMENTARY TARGET INDICATORS}

So far the analysis has been restricted to maternal mortality, but the question as to whether this indicator actually is the most appropriate marker of women's health cries out for an answer. Although fertility can be seen to have a direct influence on maternal mortality, for example, posing the question in this way compromises a fuller appreciation of the role of fertility to women's health and well being.
Without going into the plethora of socioeconomic and cultural linkages between fertility and women's well being, the maternal mortality rate does not even capture the full medical risk which women face in their role as reproducers of the human race. The maternal mortality rate is defined as the number of maternal deaths per 100,000 live births (within one year on average), which means that it reflects the risks associated with individual deliveries but does not take into account the fact that the number of pregnancies and deliveries a woman goes through alters the overall risks she faces. That is better captured by the concept of lifetime risk, which takes in to account both the risk of 


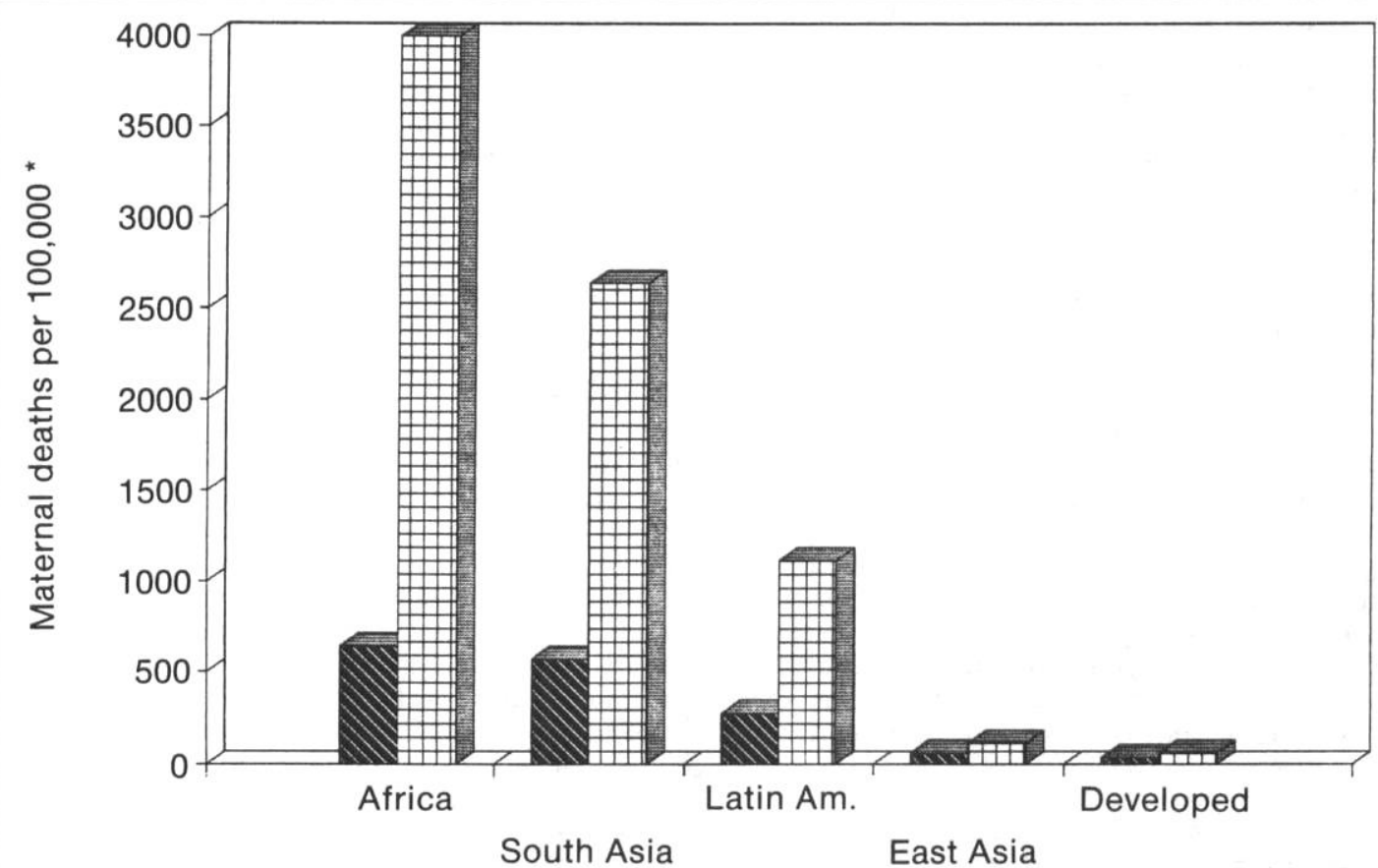

Region

MIIN MMR Lifetime MMR

Note: a/ better known as the Lifetime Risk (of a woman dying from maternal causes), when expressed as a fraction or a ratio. For example, the fact the 4,000 African women, out of 100,000, die from pregnancy related causes (on average) means that they face a Lifetime Risk of $4 / 100$, or $1 / 25$. The corresponding figure for women in developed nations is $1 / 1,750$.

$\star=$ per 100,000 live births for the maternal mortality rate, and = per 100,000 women aged 15-45 within a lifetime on average, for lifetime risk of maternal death.

Source: Based WHO estimates in WHO, 1989, Preventing Maternal Deaths, E. Royston (ed.).

individual childbirths and the average number of children women produce, in a lifetine. ${ }^{5}$ Figure 2 provides a rough profile of maternal mortality rates as compared with lifetime risks faced by women, on average, by major regions, based on available estimates by the World Health Organisation and the World Bank.

It is hard to determine any obvious declining trends in maternal mortality in most Third World Regions,

"In fact, the maternal mortality rate does not even measure risks associated with pregnancy in a very satisfactory way, since abortions and stillbirths are excluded from the denominator. The lifetime risk except for in Latin America. The same is not the case for lifetime risk, since total fertility rates have decreased on a global level, although in parts of the Arab World and in many of the poorest countries in sub-Saharan Africa fertility is not declining (United Nations 1989).

There is, however, evidence of recent reductions in the maternal mortality rate in some individual countries

of maternal death, on the other hand, avoids this problem, since it multiplies the maternal mortality rate with the total fertility rate, which also excludes abortions and stillbirths (from the numerator). 
such as China, Sri Lanka or Mauritius, and these also tend to have experienced major recent declines in fertility rates. Fertility impacts on lifetime risk in two separate ways; one directly through the total number of births a woman is likely to give, and the second, indirectly through its effect on maternal mortality rate in Africa is estimated to be just over 20 times as large as it is in developed countries, the lifetime risk for women of dying in connection with childbirth is approximately 70 times higher.

Lifetime risk is a more useful all-round indicator of women's reproductive health than is maternal mortality. This is not only because it captures the interrelationship between fertility and pregnancy related mortality better than the maternal mortality rate does, or because it accentuates regional variations and inter-temporal trends, but primarily because it treats the woman rather than the birth as the subject. That is, it measures the full risk of death faced by the average woman (in her capacity as the bearer of children) rather than those associated with the disembodied process of giving birth. After all it seems odd that the infant mortality rate should measure the full risks of death faced by the infant, whereas the maternal mortality rate does not measure those faced by the mother.

\section{INDICATORS FOR MEASURING COMMITMENT AND PROGRESS}

The indicators of maternal mortality, fertility and lifetime risk of maternal death are all health status indicators, and could therefore be conceived of as target indicators. In order to improve the health status of women, however, it is also necessary to identify some intermediate indicators, or input and output indicators, to use the language of the logical framework. Inputs would include expenditures and the amount and allocation of other resources, such as equipment and manpower. Output indicators (sometimes called performance indicators) would include the proportion of births attended, the proportion of pregnant women attending antenatal care or receiving immunizations and the contraceptive prevalence rate. All these can be used to monitor progress as well as to measure the commitment of governments to improve maternal health, in a broad sense. There are of course also intermediate operational performance indicators, between the input and output indicators listed here, which may be used in the monitoring and evaluation of specific projects and programmes.

\subsection{The allocation of expenditures}

The only input indicator this article addresses is the allocation of expenditures, in the interest of brevity. In general the share of central government expenditures going to health and education has declined in the 1980s, at the same time as the proportion going to defence has increased, on the whole, in developing countries. The share of health budgets going to Primary Health Care may be used as a proxy for commitment to maternal health, since $\mathrm{MCH}$ (even if not always family planning) usually form a central part of Primary Health Care. There is precious little evidence of any overall increases in the proportion of health budgets allocated to Primary Health Care in any major region of the Third World from 1985 to 1988 (WHO 1989b). In fact, the Western Pacific was the only region, with the exception of Europe, where more countries reported increases than reported decreases or unchanged shares of health resources going to Primary Health Care. South-East Asian countries on the whole allocate a far greater share of their health budgets to Primary Health Care than do countries in other regions of the Third World (WHO $1989 \mathrm{~b}$ ). In general, the least developed countries spend smaller proportions of their health budgets on Primary Health Care than do other developing countries; only about 54 per cent of the former, and over 67 per cent of the latter, are reported to spend more than 30 per cent of their health budgets on primary health services.

The responsibility for this pattern of expenditures can not be placed squarely on the shoulders of developing countries alone, however. International assistance has tended to reinforce this neglect of social sector development. For example, aid going to health, nutrition and family planning decreased by one third from 7.5 per cent of all aid in 1979 to 5 per cent in 1987 , and for education it decreased from 17 to 10.5 per cent in the same period (UNICEF 1990). This is not the end of the matter, however, since not all expenditure on health will benefit mothers and infants. The World Health Organisation has estimated that only some 20 per cent of international resources spent on health care goes to Maternal and Child Health and Family Planning (WHO 1987). This means that out of all aid in the mid-1980s only about one per cent was spent on programmes related to women's health. This seems to be at odds with popular perceptions and the image of international assistance, perpetuated by mass media.

\subsection{Proportion of childbirths attended by trained health staff}

The proportion of childbirths attended by trained personnel is probably the most relevant output indicator of efforts to improve maternal health, the other being the proportion of mothers attending antenatal care. With respect of the former, there seems to have been some improvement globally, even if progress is more doubtful in poorer countries. More countries in Africa reported a decrease in the proportion of births attended by trained health staff than reported an increase, between 1985 and 1988, according to the WHO (WHO 1989b). In South-East Asia, the number of countries reporting increases was 
equal to the number of countries reporting decreases, for the same period. In other regions improvements were recorded overall.

Whereas the majority of women in the least developed parts of the world live in countries where less than 20 per cent of all births are attended by trained personnel, in industrialised countries the vast majority of women enjoy a coverage of birth attendance above 80 per cent, as is shown in Figure 3. This means that a pregnant woman in one of the least developed countries stands a less than one in five chance of receiving professional help during labour. Considering the maldistribution of health staff (and other resources) in relation to population in most developing countries, the chances of a woman living in a rural area receiving professional help may be close to zero, even though the chances of her needing those services are usually higher than for an urban woman. One wonders how this compares with the average percentage coverage of European cows being attended by veterinarians at calfing.

\subsection{The provision of family planning services}

The contraceptive prevalence rate is an important

Figure 2: Maternal mortality rates and the average lifetime mortality rate a/ $^{2}$ from maternal causes, by major regions

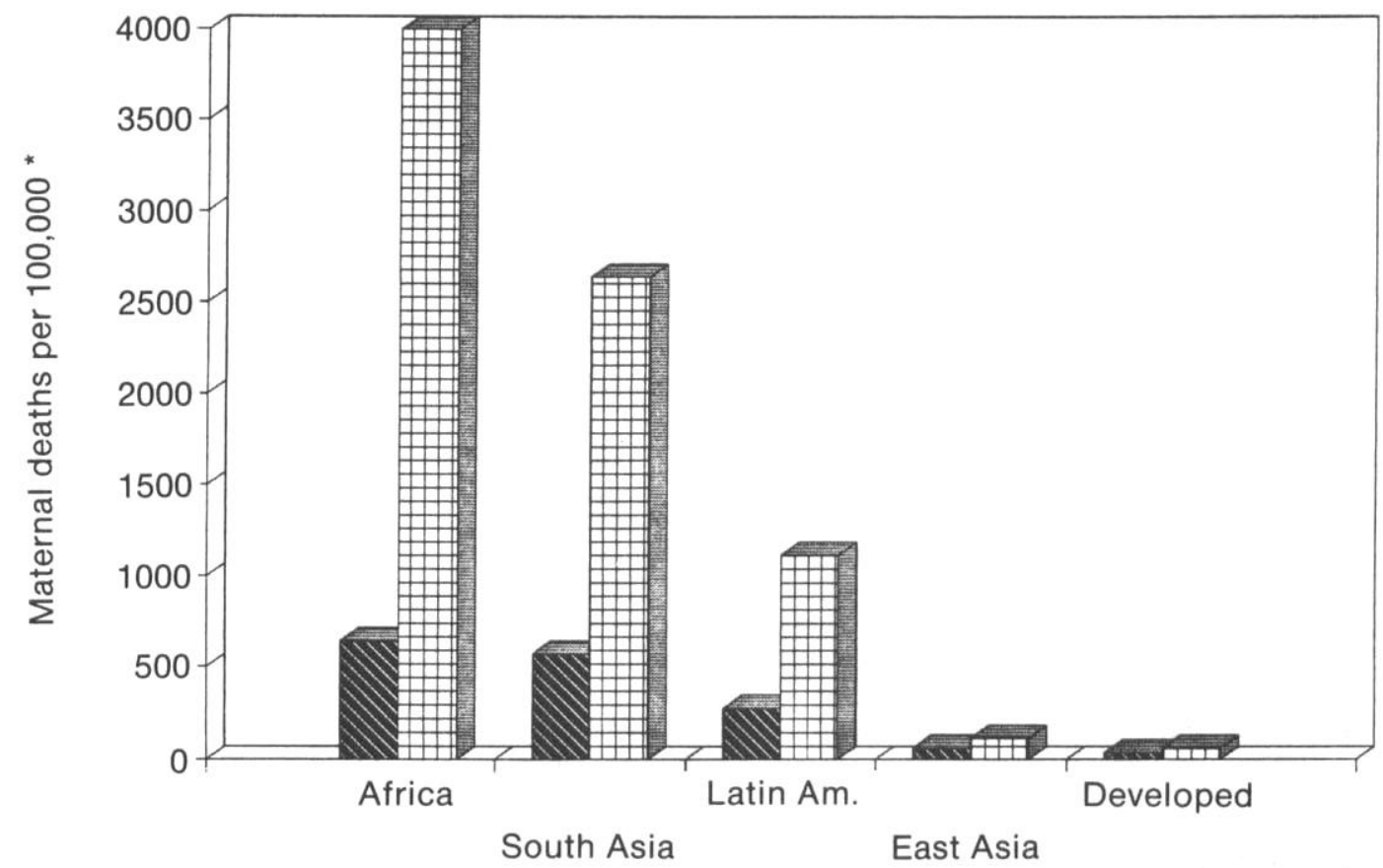

Region

MIII MMR Lifetime MMR

Note: a/ better known as the Lifetime Risk (of a woman dying from maternal causes), when expressed as a fraction or a ratio. For example, the fact the 4,000 African women, out of 100,000, die from pregnancy related causes (on average) means that they face a Lifetime Risk of $4 / 100$, or $1 / 25$. The corresponding figure for women in developed nations is $1 / 1,750$.

$\star=$ per 100,000 live births for the maternal mortality rate, and = per 100,000 women aged $15-45$ within a lifetime on average, for lifetime risk of maternal death.

Source: Based WHO estimates in WHO, 1989, Preventing Maternal Deaths, E. Royston (ed.). 
output indicator, which relates to the provision of family planning services. This indicator gives us a broader reflection of a society's attitude towards women's own health needs (as well as other needs) rather than merely from the point of view of being incubators for the next generation. Contraceptive prevalence (the percentage of women, aged 15 to 45 , who currently use modern methods of contraception) is generally low in very poor countries, usually below or around 20 per cent, and it tends to rise with per capita GNP, to levels like 83 per cent in the UK, for example. However some countries have unusually high rates of contraceptive prevalence, with respect to their levels of GNP. Examples include Zimbabwe (38 per cent), Indonesia (48 per cent), Sri Lanka (62 per cent), Thailand ( 66 per cent), Costa Rica (70 per cent) or China (74 per cent) (UNICEF 1990). One aspect which these countries have in common is their broad multisectoral strategies in development planning, as well as strong efforts at reforming their health sectors along lines similar to those of Primary Health Care, drawn up at Alma-Ata in 1978.

Family planning has an integral role to play in the reduction of maternal mortality, which is not to say that this is its most important role. It is, however, only achieving a small fraction of its potential, since some 300 million couples who claim to not want any more children are nevertheless not using contraception, according to the World Fertility Survey, WFS (Sai 1986). Unwanted pregnancies tend to be high risk pregnancies and often lead to dangerous illicit abortions. Official policies towards family planning and the legal status of abortion, both, not only affect the health of women directly, but also reflect how a society values its women and their health.

\subsection{The availability and use of indicators as an indicator}

Having described various indicators in a language drawn from the logical framework, it seems highly appropriate to step outside such formal frameworks for a brief moment and consider the more lateral aspects of the use of such indicators. The mere choice and range of available indicators itself reflects how governments and policy makers regard the relative importance of different problems in health. For example, infant mortality rates have been the topic of extensive research and they have been widely reported since the end of the 1970s, whereas meaningful magnitudes of resources devoted to the problem of maternal mortality only began to re-emerge after the mid-1980s. On the other hand, the fact that maternal mortality is still the only widely reported indicator of women's health status, reflects the fact that women's health remains an area in need of further development, even today.

Another highly relevant health problem, which has attracted more attention and resources for research than any other in recent years, is of course the escalating AIDS pandemic. AIDS is now the leading cause of death for women aged between 20 and 40 in several major cities in Western Europe and in the Americas, as well as in some countries in sub-Saharan Africa (Chin 1990). It is clear that AIDS related mortality is likely to overtake maternal mortality in many countries, but it would also seem that the two problems have obvious connections (both being in the field of reproductive health). However, it is not clear how responses to this alarming epidemic are to be coordinated with strategies to deal with the more silent and chronic epidemics of high maternal mortality and fertility in developing countries. Does AIDS impose constraints in terms of narrowing the focus and draining resources, or does it provide a new lease of life for family planning and reproductive health in developing countries? Even on a technical level the question of appropriate choices of methods of contraception remains very complex and largely unresolved, even today (Edstrom and Mann 1987).

\section{CONCLUSION}

It is high time to begin to portray and measure women's health in a way which actually considers women's health for its own sake, rather than for some other purpose, such as population control or its opposite (i.e. helping infants to live longer in poverty and deprivation). The focus in women's health clearly needs to be broadened not only from maternal health care to reproductive health, including family planning, fertility and abortion issues etc., but also to a level at which women's health is identified not merely by women's reproductive role, but in a more holistic way (taking into account broader socioeconomic and cultural concerns and aspirations). That is, although reproductive health and fertility must clearly remain a central concern for any meaningful elaboration of the topic of women's health, it should not necessarily be the be all and end all of the subject, since women's well being clearly cannot be reduced to successful childbearing ... or the lack of it. In fact, in order to get to the bottom of the problem of reproductive health itself, broader and more critical gender sensitive analysis may be required. In other words, unless the issues and priorities for research in reproductive health actually reflect the interests, needs and aspirations of women in the Third World, development in the field of women's health is likely to be stunted. 


\section{REFERENCES}

Acsadi, G. T. F. and Johnson-Acsadi, G., 1986, Optimum Conditions for Childbearing, London, IPPF

Berardi, J. C., Richard, A., Dianhan, Y. and Papiernik, E., 1989, 'Decentralization of maternity care', World Health Forum, Switzerland, Vol 10 No 3/4:322-6

Chen, L. C. et al., 1974, 'Maternal mortality in rural Bangladesh', Studies in Family Planning, Vol 5 No 11:334-341

Chin, J., 1990, 'Current and future dimensions of the HIV/AIDS pandemic in women and children', The Lancet, No 336:221-224

Edström, K. G. B. and Mann, J. M., 1987, 'Acquired Immuno-Deficiency Syndrome (AIDS): its implications for women and children', Technical background paper prepared for the International Conference on Better Health for Women and Children through Family Planning, Nairobi, Kenya, October 1987

Halstead, S. B., Walsh, J. A. and Warren, K. S., 1985, Good Health at Low Cost, New York, Rockefeller Foundation

Hobcraft, J., 1987, 'Does family planning save children's lives?' Technical background paper prepared for the International Conference on Better Health for Women and Children through Family Planning, Nairobi, Kenya, October 1987

Kwast, B. E., 1989, 'Maternal mortality: levels, causes and promising interventions', Fournal of Biosocial Science Supplement No 10:51-67

Liskin, L. S., 1980, 'Complications of abortions in developing countries', Population Reports, Series F, No 7

Maine, D. et al., 1987, Prevention of Maternal Deaths in Developing Countries: Programme Options and Practical Considerations, New York, University of Columbia
Mauldin, W. P. and Segal, S. J., 1988, 'World trends in contraceptive use, by method and their relationship to fertility'. The Population Council for Policy Studies Working Paper No 139, New York, The Council

Potts, M. et al., 1977, Abortion, Cambridge, Cambridge University Press

Sai, F. T., 1986, 'Family planning and maternal health care: a common goal', World Health Forum Vol 7 No 4:315-340

UNICEF, 1985, The State of the World's Children, 1985, Oxford, Oxford University Press

-1990, The State of the World's Children, 1990, Oxford, Oxford University Press

-1991, The State of the World's Children, 1991, Oxford, Oxford University Press

United Nations, D. o. I. E. a. S. A., 1989, 'World Population Prospects, 1988', Population Studies No 106, New York, United Nations

-1990, 'Integrating Development and Population Planning', Population Newsletter, June 1990

WHO, 1979, International Classification of Diseases, Injuries and Causes of Death (ICD9)

-1987, Safe Motherhood: an information kit

-1989a, 'Preventing Maternal Deaths'. (Eds.) E. Royston and S. Armstrong, Geneva, WHO

-1989b, 'Progress towards health for all', World Health Statistics Quarterly Vol 42 No 4:197-214

Winikoff, B., 1988, 'Women's health: an alternative perspective for choosing interventions', Studies in Family Planning Vol 19 No 4

World Bank, 1988, World Development Report, 1988, Oxford, Oxford University Press 